\title{
A European multicentre photopatch test study
}

\section{The European Multicentre Photopatch Test Study (EMCPPTS) Taskforce ${ }^{1}$}

Photobiology Unit, Department of Dermatology, Ninewells Hospital, Dundee DD1 9SY, U.K.

\section{Summary}

\section{Correspondence \\ Alastair C. Kerr. \\ E-mail: a.kerr@dundee.ac.uk}

\section{Accepted for publication \\ 11 January 2012}

\section{Funding sources}

Chemotechnique Diagnostics, Vellinge, Sweden and L'Oréal Research and Innovation, Clichy, France.

\section{Conflicts of interest}

None declared.

${ }^{1} A$ list of the members of the EMCPPTS Taskforce and their affiliations is given in Appendix.

DOI $10.1111 /$ j.1365-2133.2012.10857.x
Background The two most common agent groups currently responsible for photoallergic contact dermatitis (PACD) are organic ultraviolet (UV) absorbers in sunscreens and topical nonsteroidal anti-inflammatory drugs (NSAIDs). However, availability of information on the photoallergenic potential of these agents is scarce.

Objectives To obtain current information on the frequency of PACD to 19 organic UV absorbers and five topical NSAIDs, including newer agents, in common usage in Europe.

Methods A prospective, multicentre photopatch test study was conducted with 1031 patients attending for investigation of suspected PACD in 30 centres across 12 European countries.

Results A total of 346 PACD reactions in $200(19 \cdot 4 \%)$ subjects occurred. PACD was most commonly caused by the topical NSAIDs, ketoprofen (128 subjects) and etofenamate (59 subjects). Of the organic UV absorbers, octocrylene, benzophenone-3 and butyl methoxydibenzoylmethane most frequently elicited PACD. The 'newer' organic sunscreen absorbers rarely led to PACD. There appeared to be an association between the agents ketoprofen, octocrylene and benzophenone3 , with several subjects developing PACD to two or all three agents concomitantly. Allergic contact dermatitis (ACD) was less commonly observed than PACD, comprising 55 reactions in $47(5 \%)$ subjects. Irritant reactions and photoaugmentation and photoinhibition of ACD occurred infrequently.

Conclusions The European multicentre photopatch test study has provided current information on the relative frequency of PACD to common photoallergens. Such data will be of value when deciding on which agents to include in a future European 'baseline' photopatch test series.
Photoallergic contact dermatitis (PACD) is the delayed-type hypersensitivity reaction which occurs when an exogenous agent (photoallergen) is applied to the skin and subsequently exposed to ultraviolet (UV) and/or visible radiation. Historically, several agents have been identified as photoallergens, some of which have subsequently been removed from the European marketplace. Currently, the two most common agent groups are organic UV absorbers used in sunscreens and topical nonsteroidal anti-inflammatory drugs (NSAIDs). ${ }^{1}$ The incidence of PACD is unknown, but it is thought to be uncommon with frequencies of $2-10 \%$ reported among patients referred for investigation of a photoexposed-site dermatosis. ${ }^{2-4}$ The investigation of choice for diagnosing PACD is photopatch testing (PPT), for which a European consensus methodology has existed for several years. ${ }^{5}$ However, in contrast to conventional patch testing, for which several national and international 'baseline' series of allergens exist, currently no European 'baseline' PPT series has been agreed on. This is in part because limited data exist on the current most common photoallergens in Europe.

In 2007, a group of interested clinicians met in Amsterdam under the auspices of the European Society for Photodermatology and the European Society of Contact Dermatitis with the aim of setting up a European multicentre photopatch test study (EMCPPTS).

The primary objective of the study was to determine the frequency of PACD to 19 organic UV absorbers and five topical NSAIDs in common usage in Europe among patients presenting for investigation of suspected PACD using a standardized PPT technique.

\section{Materials and methods}

Several photobiology and contact dermatitis units across Europe were invited to participate. At the initial meeting, there was agreement that the total target number of subjects would 
be $>1000$ over a 1 -year period. This figure was not generated from a formal statistical sample size calculation, but based on consensus that it would provide a clinically valuable estimate of the frequency of PACD, while being practically achievable over the timescale intended.

Due to heterogeneous legislation and its interpretation across different European countries, some investigators had to seek and obtain ethical approval, whereas others did not. The latter group considered the PPT investigation as part of routine clinical care. The inclusion criteria specified that subjects must be aged 18 years or older and have sufficient understanding to give written informed consent. Those included had at least one of the following four indications for performing PPT: (i) an exposed-site dermatitis during summer months; (ii) any exposed-site dermatitis; (iii) history of a sunscreen reaction; or (iv) history of a topical NSAID skin reaction.

Exclusion criteria were: (i) potent topical steroid applied to the photopatch test site on the back in the 5 days prior to PPT; (ii) skin disease activity on the back which was too active to allow PPT; and (iii) subjects prescribed systemic immunosuppressant medication (i.e. prednisolone, methotrexate, azathioprine, ciclosporin). In addition, a relative contraindication was any patient taking photoactive medicine (e.g. thiazides, fluoroquinolones, NSAIDs, quinine) at the discretion of the clinician.

PPT was conducted according to the European consensus methodology as described previously. ${ }^{5}$ In brief, the test agents were applied to the skin of the back and removed at 24 or $48 \mathrm{~h}$, depending on the set-up at each centre. One set was then irradiated with $5 \mathrm{~J} \mathrm{~cm}^{-2}$ UVA (or less if UVA minimal erythemal dose testing revealed objective photosensitivity ${ }^{6}$ ) while the other set was covered with a UV-impermeable material. Readings of the test site could then be made at five different time points: preirradiation, immediately postirradiation, $24 \mathrm{~h}$ postirradiation, $48 \mathrm{~h}$ postirradiation and $72 \mathrm{~h}$ postirradiation or later. However, the reading made at $48 \mathrm{~h}$ postirradiation was considered the key time point and subsequent data analysis focused on this. ${ }^{3}$ Prior to any subject recruitment, all participating centres were asked to send their UVA meters via post to the coordinating centre in Dundee for calibration. This laboratory is International Organisation for Standardisation (ISO) 9001 registered and U.K. Accreditation Service (UKAS) accredited. The meters were tested using a bank of 100-W UVA lamps and calibrated using a Bentham model DM150 spectroradiometer (Bentham Instruments Ltd, Reading, U.K.) with calibration traceable to the U.K. National Physical Laboratory.

The photopatch test series of 19 organic UV absorbers and five topical NSAIDs with the concentrations used are given in Table 1. The 24 agents were donated by Chemotechnique Diagnostics Ltd (Vellinge, Sweden). The 19 UV absorbers are all in common usage and among the 26 sunscreening agents currently permitted for use in cosmetic products by the European Commission. ${ }^{7}$ All UV absorbers were tested at a concentration of $10 \%$, except benzophenone-4, which was used at a $2 \%$ concentration due to the irritant potential of higher concentrations discovered during a pilot irritancy study. ${ }^{8}$ The
Table 1 The European multicentre photopatch test study test agents, with chemical abstracts service (CAS) numbers and concentrations

\begin{tabular}{|c|c|c|}
\hline Test agent $^{\mathrm{a}}$ & CAS number & $\begin{array}{l}\text { Concentration } \\
(\%)\end{array}$ \\
\hline Butyl methoxydibenzoylmethane & 70356-09-1 & 10 \\
\hline Homosalate & 8045-71-4 & 10 \\
\hline 4-Methylbenzylidene camphor & $36861-47-9$ & 10 \\
\hline Benzophenone-3 & $131-57-7$ & 10 \\
\hline Ethylhexyl methoxycinnamate & $5466-77-3$ & 10 \\
\hline $\begin{array}{l}\text { Phenylbenzimidazole sulfonic } \\
\text { acid }\end{array}$ & 27503-81-7 & 10 \\
\hline Benzophenone-4 & $4065-45-6$ & 2 \\
\hline Drometrizole trisiloxane & $155633-54-8$ & 10 \\
\hline Octocrylene & $6197-30-4$ & 10 \\
\hline Ethylhexyl salicylate & $118-60-5$ & 10 \\
\hline Ethylhexyl triazone & $88122-99-0$ & 10 \\
\hline Isoamyl-p-methoxycinnamate & 71617-10-2 & 10 \\
\hline $\begin{array}{l}\text { Terephthalylidene dicamphor } \\
\text { sulfonic acid }\end{array}$ & $90457-82-2$ & 10 \\
\hline $\begin{array}{l}\text { bis-Ethylhexyloxyphenol } \\
\text { methoxyphenyl triazine }\end{array}$ & $187393-00-6$ & 10 \\
\hline $\begin{array}{l}\text { Methylene bis-benzotriazolyl } \\
\text { tetramethylbutylphenol }\end{array}$ & $103597-45-1$ & 10 \\
\hline $\begin{array}{l}\text { Diethylamino hydroxybenzoyl } \\
\text { hexyl benzoate }\end{array}$ & $302776-68-7$ & 10 \\
\hline $\begin{array}{l}\text { Disodium phenyl } \\
\text { dibenzimidazole tetrasulfonate }\end{array}$ & 180898-37-7 & 10 \\
\hline Diethylhexyl butamido triazone & $154702-15-5$ & 10 \\
\hline Polysilicone-15 & 207574-74-1 & 10 \\
\hline Ketoprofen & $22071-15-4$ & 1 \\
\hline Etofenamate & $30544-47-9$ & 2 \\
\hline Piroxicam & $36322-90-4$ & 1 \\
\hline Diclofenac & $15307-79-6$ & 5 \\
\hline Ibuprofen & $15687-27-1$ & 5 \\
\hline Control (Pet) & $\mathrm{n} / \mathrm{a}$ & $\mathrm{n} / \mathrm{a}$ \\
\hline \multicolumn{3}{|c|}{$\begin{array}{l}\text { a International Nomenclature of Cosmetic Ingredients (INCI) } \\
\text { name (for organic ultraviolet absorbers). Pet, petrolatum; } \mathrm{n} / \mathrm{a} \text {, } \\
\text { not applicable. }\end{array}$} \\
\hline
\end{tabular}

concentrations of the topical NSAIDs used were chosen after consensus was reached by several members at the initiation meeting who had expertise in testing with these agents. All agents were prepared in petrolatum except terephthalylidene dicamphor sulfonic acid which was prepared in water, as it has a low $\mathrm{pH}$ which requires the addition of a neutralizing agent to prevent irritant reactions.

All PPT reactions were graded using the International Contact Dermatitis Research Group (ICDRG) system. ${ }^{9}$ Investigators were asked to assign relevance to any positive reactions seen whenever possible using the COADEX system. ${ }^{10}$ This classifies positive reactions as follows: $\mathrm{C}$, current relevance; O, old/past relevance; $\mathrm{A}$, an active sensitization reaction; $\mathrm{D}$, unknown relevance; E, history of exposure but not resulting in dermatitis; $\mathrm{X}$, cross-reaction with another test agent. A single-sided A4-size paper proforma was used to record anonymous data for each subject (Appendix S1; see Supporting information). 
The study proforma allowed space for inclusion of up to three of a subject's 'own agents' to be tested 'as is', e.g. commercial sunscreens. When completed, each proforma was faxed or posted to the coordinating centre in Dundee. The information included on all proformas received was entered into a secure database for subsequent data analysis.

\section{Results}

When using the above PPT methodology and ICDRG reaction grading system, interpretation allows six possible reaction patterns to be determined, as previously described. ${ }^{3}$ These are $\mathrm{PACD}$, allergic contact dermatitis (ACD), photoaugmentation of $\mathrm{ACD}$, photoinhibition of $\mathrm{ACD}$, irritant response (IR) and negative response. In the present study, all '+' ICDRG reactions were discounted for the purpose of data analysis.

\section{Baseline data}

A total of 1031 subjects were recruited, of whom 715 $(69 \cdot 4 \%)$ were female. The median age of subjects was 46 years (range 18-92). Regarding photopatch application time, this was $24 \mathrm{~h}$ in $679(65.9 \%)$ subjects and $48 \mathrm{~h}$ in 347 $(33.7 \%)$, with no duration specified in five subjects. The dose of UVA used for irradiation was $5 \mathrm{~J} \mathrm{~cm}^{-2}$ in 977 (94.8\%) subjects, with the remaining 54 subjects receiving $<5 \mathrm{~J} \mathrm{~cm}^{-2}$.

Subjects were recruited from 30 centres across 12 European countries. The number of subjects recruited by each centre is given in Figure 1 which shows that two U.K. centres accounted for $439(42 \cdot 6 \%)$ of the 1031 subjects recruited. The recruitment period had to be extended from 12 to 32 months (August 2008 to February 2011). One factor that contributed to the delay in subject recruitment at some centres was the completion of paperwork required to comply with the EU clinical trials directive. ${ }^{11}$

\section{Photoallergic contact dermatitis reactions}

A total of 346 PACD reactions in 200 subjects were recorded. Therefore, $19 \cdot 4 \%$ of subjects had at least one PACD reaction, a frequency higher than in many previous studies. There was great variation in the frequency of PACD at each centre, ranging from $0 \%$ to $90.9 \%$ of subjects investigated (Appendix S2; see Supporting information). The number of PACD reactions recorded for each agent, with the corresponding ICDRG grade of the reaction in the irradiated set is given in Table 2. Of the 346 PACD reactions, 343 were assigned COADEX relevance, as follows: $\mathrm{C}=152 ; \mathrm{O}=38 ; \mathrm{A}=1 ; \mathrm{D}=110 ; \mathrm{E}=3 ; \mathrm{X}=39$ (Appendix S3; see Supporting information). The number of PACD reactions to ketoprofen, etofenamate, octocrylene and benzophenone-3 were high enough to allow analysis of PACD rates to each agent in each country (Appendix S4; see Supporting information). If reactions to NSAIDs were excluded, there were 148 PACD reactions in 95 subjects to the 19 organic UV absorbers, giving a lower PACD rate of $9 \cdot 2 \%$.

The frequency of PACD appeared to vary with duration of patch application. Of the 679 subjects who had patches applied for $24 \mathrm{~h}, 94(13.8 \%)$ had at least one PACD reaction, whereas of the 347 subjects who had patches applied for $48 \mathrm{~h}, 105(30 \cdot 2 \%)$ had at least one PACD reaction. In the case of gender, of the 715 women recruited, $118(16.5 \%)$ had at least one PACD reaction, compared with $82(26 \cdot 2 \%)$ of the 313 male subjects. The effect of age on the frequency of PACD was analysed by grouping subjects into 10 -year blocks, as given in Table 3. After the age group 28-37 years, the frequency of PACD gradually decreased with age, except among subjects aged 78 years and older.

The frequency of PACD by diagnosis is shown in Table 4. As regards the 54 subjects in whom a dose $<5 \mathrm{~J} \mathrm{~cm}^{-2}$ was used for irradiation, the median dose used was $2.5 \mathrm{~J} \mathrm{~cm}^{-2}$ (range $0 \cdot 25-4)$ and nine $(16 \cdot 7 \%)$ had at least one PACD reaction. When the indication for testing was examined, subjects who gave a history of reacting to a sunscreen or topical NSAID had higher rates of PACD than those with an exposedsite dermatitis or dermatitis in summer months (Table 5). Further analysis showed that of the 139 subjects with a history of reacting to a topical NSAID, $97(69 \cdot 8 \%)$ had at least one PACD reaction to one of the five NSAID test agents compared with $164(15 \cdot 9 \%)$ subjects of the total 1031 subjects recruited.

There appeared to be an association between PACD reactions to the three agents, ketoprofen, benzophenone-3 and octocryl-
Fig 1. Recruitment of subjects in the European multicentre photopatch test study by centre (centres 1 and 2 were in the U.K.).

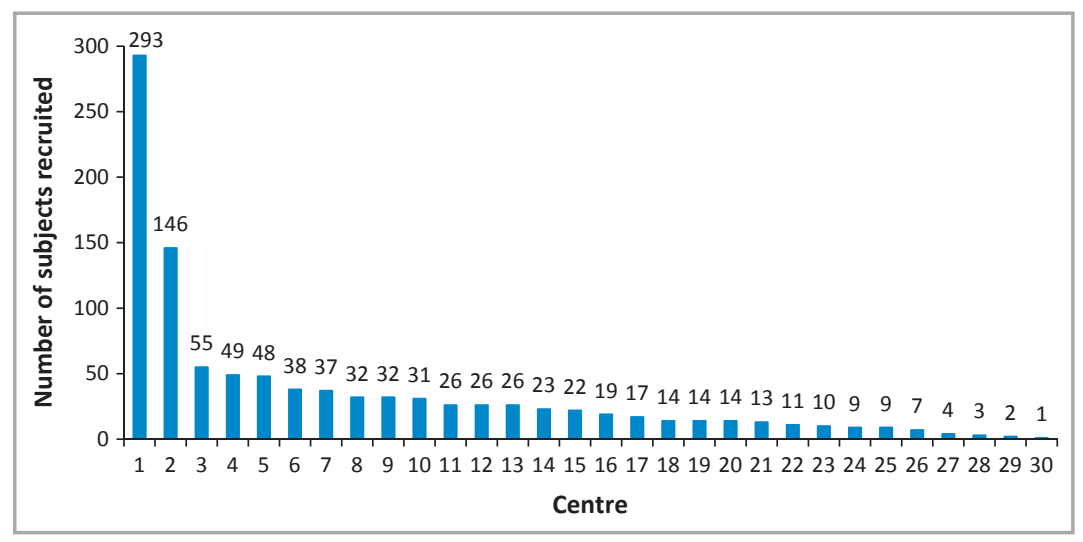


Table 2 Photoallergic contact dermatitis (PACD) reactions to the 19 organic ultraviolet (UV) absorbers and five topical nonsteroidal antiinflammatory drugs in the European multicentre photopatch test study at $48 \mathrm{~h}$ postirradiation, with International Contact Dermatitis Research Group (ICDRG) grading of reactions in the irradiated set of test agents

\begin{tabular}{|c|c|c|c|c|}
\hline \multirow[b]{2}{*}{ Test agent $^{\mathrm{a}}$} & \multirow{2}{*}{$\begin{array}{l}\text { Number of } \\
\text { subjects } \\
\text { with } \\
\text { PACD } \\
\text { reaction }\end{array}$} & \multicolumn{3}{|c|}{$\begin{array}{l}\text { ICDRG grade of } \\
\text { PACD reaction } \\
\text { in irradiated set }\end{array}$} \\
\hline & & + & ++ & +++ \\
\hline Ketoprofen & 128 & 23 & 65 & 40 \\
\hline Etofenamate & 59 & 32 & 24 & 3 \\
\hline Octocrylene & 41 & 11 & 19 & 11 \\
\hline Benzophenone-3 & 37 & 14 & 18 & 5 \\
\hline Butyl methoxydibenzoylmethane & 18 & 10 & 6 & 2 \\
\hline Isoamyl-p-methoxycinnamate & 10 & 4 & 6 & 0 \\
\hline Ethylhexyl methoxycinnamate & 7 & 3 & 3 & 1 \\
\hline $\begin{array}{l}\text { Methylene bis-benzotriazolyl } \\
\text { tetramethylbutylphenol }\end{array}$ & 5 & 5 & 0 & 0 \\
\hline Piroxicam & 5 & 4 & 1 & 0 \\
\hline $\begin{array}{l}\text { Terephthalylidene dicamphor } \\
\text { sulfonic acid }\end{array}$ & 4 & 2 & 2 & 0 \\
\hline $\begin{array}{l}\text { Diethylamino hydroxybenzoyl } \\
\text { hexyl benzoate }\end{array}$ & 4 & 2 & 2 & 0 \\
\hline Ibuprofen & 4 & 3 & 1 & 0 \\
\hline 4-Methylbenzylidene camphor & 3 & 1 & 2 & 0 \\
\hline Benzophenone-4 & 3 & 1 & 2 & 0 \\
\hline Ethylhexyl triazone & 3 & 3 & 0 & 0 \\
\hline $\begin{array}{l}\text { bis-Ethylhexyloxyphenol } \\
\text { methoxyphenyl triazine }\end{array}$ & 3 & 1 & 1 & 1 \\
\hline $\begin{array}{l}\text { Disodium phenyl } \\
\text { dibenzimidazole tetrasulfonate }\end{array}$ & 3 & 2 & 1 & 0 \\
\hline Ethylhexyl salicylate & 2 & 2 & 0 & 0 \\
\hline Diclofenac & 2 & 1 & 1 & 0 \\
\hline Homosalate & 1 & 1 & 0 & 0 \\
\hline Drometrizole trisiloxane & 1 & 0 & 1 & 0 \\
\hline Polysilicone-15 & 1 & 1 & 0 & 0 \\
\hline $\begin{array}{l}\text { Phenylbenzimidazole sulfonic } \\
\text { acid }\end{array}$ & 0 & 0 & 0 & 0 \\
\hline Diethylhexyl butamido triazone & 0 & 0 & 0 & 0 \\
\hline Control (Pet) & 2 & 2 & 0 & 0 \\
\hline Total & 346 & 128 & 155 & 63 \\
\hline
\end{tabular}

ene, as given in Table 6. Further analysis of COADEX relevance in subjects who reacted to two or all three of these agents, showed that ketoprofen was commonly assigned current or old relevance with octocrylene and/or benzophenone-3 assigned as cross-reactions (Appendix S5; see Supporting information).

\section{Other reaction patterns}

In comparison to PACD, ACD was much less frequent, with a total of 55 reactions recorded in $47(4 \cdot 6 \%)$ subjects. Nine of the 24 test agents did not lead to any ACD reactions. The number of $\mathrm{ACD}$ reactions reported for the remaining 15
Table 3 Frequency of photoallergic contact dermatitis (PACD) reactions by age group

\begin{tabular}{|c|c|c|c|}
\hline \multirow{2}{*}{$\begin{array}{l}\text { Subject } \\
\text { age } \\
\text { (years) }\end{array}$} & \multirow{2}{*}{$\begin{array}{l}\text { Total } \\
\text { number } \\
\text { of subjects }\end{array}$} & \multicolumn{2}{|c|}{$\begin{array}{l}\text { Subjects with at least } \\
1 \text { PACD reaction }\end{array}$} \\
\hline & & $\mathrm{n}$ & $\%$ \\
\hline $18-27$ & 117 & 20 & $17 \cdot 1$ \\
\hline $28-37$ & 191 & 45 & $23 \cdot 6$ \\
\hline $38-47$ & 243 & 53 & $21 \cdot 8$ \\
\hline $48-57$ & 205 & 39 & 19 \\
\hline $58-67$ & 177 & 25 & $14 \cdot 1$ \\
\hline $68-77$ & 80 & 11 & $13 \cdot 8$ \\
\hline $78-87$ & 17 & 6 & $35 \cdot 3$ \\
\hline $88-97$ & 1 & 1 & 100 \\
\hline
\end{tabular}

Table 4 Frequency of photoallergic contact dermatitis (PACD) reactions by diagnosis

\begin{tabular}{|c|c|c|c|}
\hline \multirow[b]{2}{*}{ Diagnosis } & \multirow{2}{*}{$\begin{array}{l}\text { Total } \\
\text { number } \\
\text { of } \\
\text { subjects }\end{array}$} & \multicolumn{2}{|c|}{$\begin{array}{l}\text { Subjects with at } \\
\text { least } 1 \text { PACD } \\
\text { reaction }\end{array}$} \\
\hline & & $\mathrm{n}$ & $\%$ \\
\hline Atopic dermatitis & 69 & 9 & $13 \cdot 0$ \\
\hline CAD & 31 & 6 & $19 \cdot 4$ \\
\hline PLE & 190 & 25 & $13 \cdot 1$ \\
\hline Other & 393 & 80 & $20 \cdot 4$ \\
\hline Undiagnosed & 343 & 75 & $21 \cdot 9$ \\
\hline
\end{tabular}

Table 5 Indication for testing and frequency of photoallergic contact dermatitis (PACD)

\begin{tabular}{lllr}
\hline & \multicolumn{3}{l}{$\begin{array}{l}\text { Subjects with } \\
\text { at least } 1\end{array}$} \\
& $\begin{array}{l}\text { Total } \\
\text { number } \\
\text { of }\end{array}$ & $\begin{array}{l}\text { PACD } \\
\text { reaction }\end{array}$ \\
\cline { 2 - 4 } Indication for testing & subjects & $\mathrm{n}$ & $\%$ \\
\hline Exposed-site dermatitis in & 517 & 83 & $16 \cdot 1$ \\
summer & & & \\
Any exposed-site dermatitis & 308 & 27 & $8 \cdot 8$ \\
History of sunscreen reaction & 226 & 63 & $27 \cdot 9$ \\
History of NSAID reaction & 139 & 97 & $69 \cdot 8$ \\
\hline NSAID, nonsteroidal anti-inflammatory drug. & & \\
\end{tabular}

agents, with corresponding ICDRG grade of reaction are given in Table 7. As with PACD reactions, most ACD reactions were assigned current or unknown relevance. Photoaugmentation and photoinhibition of $\mathrm{ACD}$ were relatively uncommon reaction patterns, with only 21 reactions in $18(1 \cdot 7 \%)$ subjects and 14 reactions in $11(1 \cdot 1 \%)$ subjects, respectively. Similarly, 
Table 6 The association of photoallergic contact dermatitis (PACD) reactions between ketoprofen, octocrylene and benzophenone-3 in subjects

\begin{tabular}{ll}
\hline & \\
Agent or combination & $\begin{array}{l}\text { Number of subjects } \\
\text { with positive PACD } \\
\text { of agents }\end{array}$ \\
\hline reaction to agent(s) \\
Octocrylene & 128 \\
Benzophenone-3 & 41 \\
Octocrylene and ketoprofen & 37 \\
Octocrylene and benzophenone-3 & 34 \\
Ketoprofen and benzophenone-3 & 18 \\
All three agents & 22 \\
\hline
\end{tabular}

Table 7 Allergic contact dermatitis (ACD) reactions to 15 organic ultraviolet (UV) absorbers and topical nonsteroidal anti-inflammatory drugs in the European multicentre photopatch test study at $48 \mathrm{~h}$ postirradiation, with International Contact Dermatitis Research Group (ICDRG) grading of reactions recorded

\begin{tabular}{|c|c|c|c|c|}
\hline \multirow[b]{2}{*}{ Test agent ${ }^{\mathrm{a}}$} & \multirow{2}{*}{$\begin{array}{l}\text { Number of } \\
\text { subjects } \\
\text { with ACD } \\
\text { reaction }\end{array}$} & \multicolumn{3}{|c|}{$\begin{array}{l}\text { ICDRG grade of } \\
\text { ACD reaction }\end{array}$} \\
\hline & & + & ++ & +++ \\
\hline $\begin{array}{l}\text { Methylene bis-benzotriazolyl } \\
\text { tetramethylbutylphenol }\end{array}$ & 11 & 8 & 3 & 0 \\
\hline Etofenamate & 10 & 3 & 6 & 1 \\
\hline Octocrylene & 7 & 4 & 3 & 0 \\
\hline Benzophenone-3 & 6 & 6 & 0 & 0 \\
\hline $\begin{array}{l}\text { 4-Methylbenzylidene } \\
\text { camphor }\end{array}$ & 4 & 4 & 0 & 0 \\
\hline $\begin{array}{l}\text { Terephthalylidene dicamphor } \\
\text { sulfonic acid }\end{array}$ & 4 & 4 & 0 & 0 \\
\hline Butyl methoxydibenzoylmethane & 3 & 2 & 1 & 0 \\
\hline Ethylhexyl methoxycinnamate & 2 & 2 & 0 & 0 \\
\hline Isoamyl-p-methoxycinnamate & 2 & 2 & 0 & 0 \\
\hline Ethylhexyl salicylate & 1 & 1 & 0 & 0 \\
\hline $\begin{array}{l}\text { bis-Ethylhexyloxyphenol } \\
\text { methoxyphenyl triazine }\end{array}$ & 1 & 1 & 0 & 0 \\
\hline $\begin{array}{l}\text { Diethylamino hydroxybenzoyl } \\
\text { hexyl benzoate }\end{array}$ & 1 & 0 & 0 & 1 \\
\hline $\begin{array}{l}\text { Disodium phenyl } \\
\text { dibenzimidazole tetrasulfonate }\end{array}$ & 1 & 1 & 0 & 0 \\
\hline Piroxicam & 1 & 0 & 1 & 0 \\
\hline Ibuprofen & 1 & 1 & 0 & 0 \\
\hline Totals & 55 & 39 & 14 & 2 \\
\hline
\end{tabular}

irritant reactions were rare, with only seven reactions in six $(0 \cdot 6 \%)$ subjects observed.

\section{Testing to 'own' agents}

A total of 347 of 1031 subjects had at least one 'own' agent tested in addition to the 24 test agents. For analysis, these
Table 8 Photoallergic contact dermatitis (PACD) reactions to additional 'own' agents at $48 \mathrm{~h}$ postirradiation with International Contact Dermatitis Research Group (ICDRG) gradings in the irradiated set

\begin{tabular}{|c|c|c|c|c|}
\hline \multirow[b]{2}{*}{ Agent category } & \multirow{2}{*}{$\begin{array}{l}\text { Total } \\
\text { number } \\
\text { of reactions }\end{array}$} & \multicolumn{3}{|c|}{$\begin{array}{l}\text { ICDRG grade of PACD } \\
\text { reaction in irradiated set }\end{array}$} \\
\hline & & + & ++ & +++ \\
\hline $\begin{array}{l}\text { Sunscreen/UV } \\
\text { absorber }\end{array}$ & 30 & 28 & 2 & 0 \\
\hline NSAID & 8 & 2 & 0 & 6 \\
\hline Other & 10 & 5 & 5 & 0 \\
\hline
\end{tabular}

were grouped into three main categories: (i) sunscreens 'as is' or other UV absorbers; (ii) topical NSAIDs; and (iii) 'other' agents (which included systemic medications and miscellaneous agents). A total of 48 PACD reactions in 48 (13.8\%) subjects were recorded $48 \mathrm{~h}$ postirradiation, as given in Table 8. Eleven sunscreen reactions were assigned current relevance, with 15 assigned as unknown. A total of 46 ACD reactions in $40(3.9 \%)$ subjects were recorded to additional 'own' agents $48 \mathrm{~h}$ postirradiation, 33 of which were to sunscreens, 13 to 'other agents' and zero to topical NSAIDs.

\section{Discussion}

The EMCPPTS was conducted to generate a clearer picture of which agents currently in use in this area most frequently led to PACD.

Ketoprofen led to PACD in the greatest number of subjects, which suggests it may be a potent photoallergen, as has been previously reported. ${ }^{12,13}$ The finding of likely cross-reaction in subjects between ketoprofen and benzophenone-3 has been previously reported, and can be explained by the benzophenone-like structure of ketoprofen. ${ }^{14}$ However, ketoprofen and octocrylene PACD also appear associated, but this finding cannot be as easily explained by close structural similarity. This association has stimulated experimental work investigating possible molecular mechanisms for octocrylene allergenicity. ${ }^{15}$ Although benzophenone-3 is declining in use, octocrylene use in sunscreens is increasing over time as it is effective at stabilizing butyl methoxydibenzoylmethane. ${ }^{16}$

In 2009, concerns about interactions with octocrylene led regulatory authorities in France to suspend all marketing authorizations for topical ketoprofen. This in turn led to a risk-benefit analysis by the European Medicines Agency. Although a 'positive benefit balance' was given, it can now be prescribed only by clinicians, and patients are given more warnings about the risk of developing PACD. ${ }^{17}$ The findings of the EMCPPTS appear to confirm recent reports on the association between octocrylene and ketoprofen. ${ }^{15,18}$ Such findings will be of concern to sunscreen manufacturers, whose octocrylene-containing sunscreens may lead to PACD in individuals who have been previously sensitized to ketoprofen. It appears 
that ketoprofen may belong to a category of potent photoallergens such as tetrachlorosalicylanilide and carprofen. ${ }^{19,20}$ In the case of both these agents, it was only after the agent was marketed that frequent episodes of photoallergy arose. The fact that agents like ketoprofen continue to emerge onto the marketplace questions whether current preclinical screening methods for detecting PACD are adequate.

The agent leading to PACD in the second largest number of subjects was the topical NSAID etofenamate. This anthranilic acid derivative is not available in the U.K., but is often used in Mediterranean countries. There are relatively few reports of ACD and PACD to etofenamate, but these results confirm it has photoallergenic potential. ${ }^{21}$ Most etofenamate PACD reactions were of unknown relevance and interestingly some PACD reactions to etofenamate were recorded from U.K. centres. Our observations of etofenamate reactions in Dundee led us to hypothesize that a significant number may be due to phototoxicity, rather than PACD (Fig. 2).

The UV absorbers most commonly leading to PACD were octocrylene and benzophenone-3. As discussed above, many subjects may have developed cross-reactions to ketoprofen. However, they appear to have an inherent photoallergenic po-

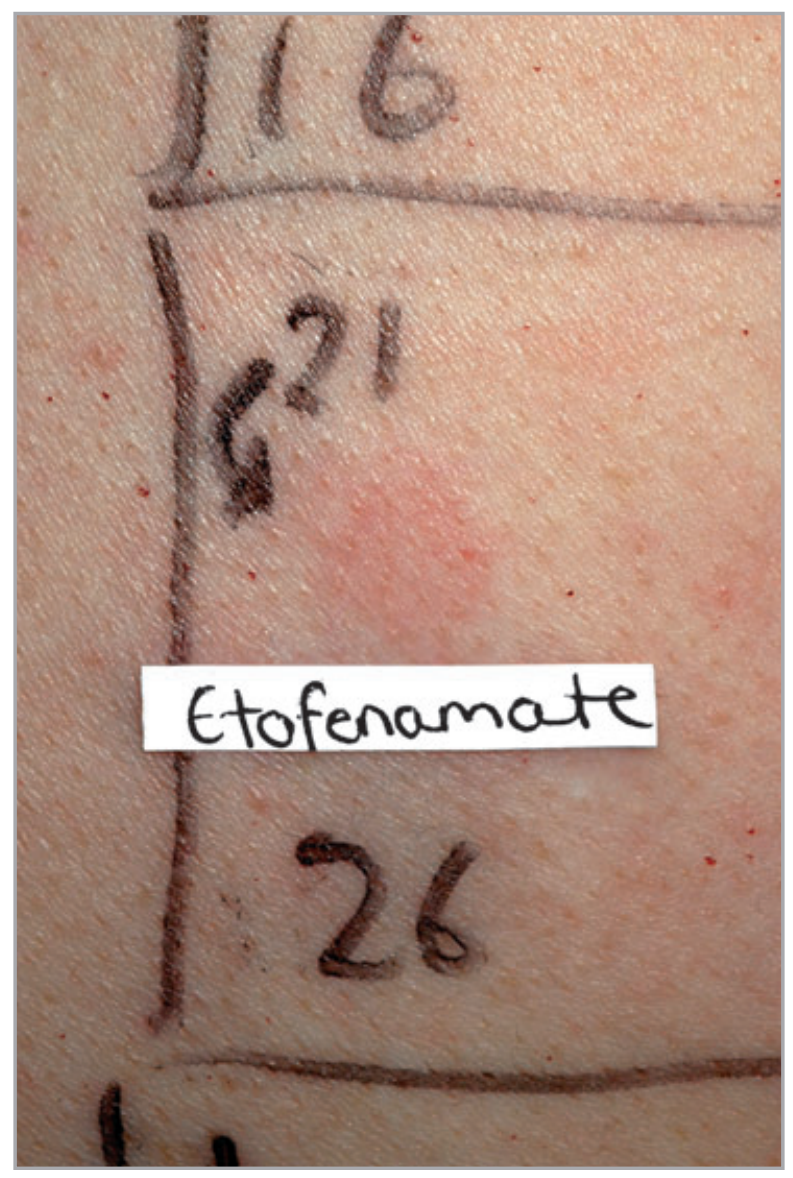

Fig 2. Close-up of etofenamate reaction at $24 \mathrm{~h}$ post irradiation in irradiated set, displaying '+' International Contact Dermatitis Research Group grade reaction. tential of their own. The high rates of PACD to butyl methoxydibenzoylmethane are likely to be at least partly due to its current high levels of usage within sunscreen preparations. ${ }^{16}$ However, its role as the most important UVA absorber in sunscreens is likely to outweigh the relatively low risk of PACD and ACD for manufacturers.

Analysis of the four agents most commonly leading to PACD suggests that PACD to ketoprofen, octocrylene and benzophenone-3 may be most common in Italy, France, Belgium and Spain. It is possible this is due to regional availability and usage pattern differences, but as above, differences in subject recruitment mean that such interpretation can only be made cautiously.

The agent most commonly leading to ACD was methylene bis-benzotriazolyl tetramethylbutylphenol (Tinosorb $\mathrm{M}^{\circledR}$; BASF, Ludwigshafen, Germany). This widely used UVB + UVA absorber is formulated as microfine nanoparticles, which require addition of the surfactant decyl glucoside. In the pilot irritancy study, it led to more positive reactions than all other agents except benzophenone- $4 .{ }^{8}$ A subsequent case of ACD to methylene bis-benzotriazolyl tetramethylbutylphenol has been reported, which attributed the problem to the decyl glucoside

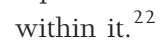

It is not possible to explain the apparent difference in frequency of PACD between male and female subjects. Certain previous studies have actually reported higher rates of ACD in female subjects, but this was thought to reflect higher levels of exposure to certain allergens, such as nickel in jewellery and fragrances in cosmetics. ${ }^{23,24}$

When analysed by diagnosis, the rates of PACD appear higher in those with chronic actinic dermatitis (CAD) than either polymorphous light eruption or atopic dermatitis, but small numbers make firm conclusions difficult. It is known that patients with $\mathrm{CAD}$ have to use sunscreens more frequently than other groups and have a higher tendency to develop ACD and PACD to agents. ${ }^{25,26}$ The inclusion of 54 subjects in whom a UVA dose of $<5 \mathrm{~J} \mathrm{~cm}^{-2}$ had to be used highlights that if PPT is performed correctly, members of this group of photosensitive subjects can be still be investigated.

When indications for testing were analysed, those with a history of reacting to a sunscreen or topical NSAID had a high frequency of PACD reactions, which confirms the importance of PPT as an investigation in these subjects. However, the less obvious indications of any exposed-site dermatitis or an exposed-site dermatitis in the summer months, should not be overlooked in patients presenting to the clinic.

Comparison of the EMCPPTS with the 2006 U.K. study by Bryden et al., ${ }^{3}$ which used the same methodology in a similar patient group, highlighted two different outcomes. Firstly, PACD rates in the EMCPPTS were much higher and, secondly, ACD rates did not match PACD rates. These differences are likely due to the inclusion of NSAIDs in the EMCPPTS and the routine inclusion of an 'as is' sunscreen in the 2006 study. ${ }^{3}$ At that time obtaining pure forms of some test agents was not possible so as a surrogate the investigators used a commercial 
SPF 60 sunscreen 'as is', which contained two such agents (terephthalylidene dicamphor sulfonic acid and drometrizole trisiloxane) for PPT. A large number of ACD and PACD reactions to this commercial sunscreen were seen, but their relevance could rarely be established.

Additionally, the 2006 study incorporated only one of the nine 'new' UV absorbers used in the EMCPPTS, ethylhexyl triazone. One of the most important findings in the present study is that all nine of the newer, larger-molecular-weight UV absorbers tested in pure form in the EMCPPTS led to PACD infrequently. This makes biological sense, as these larger molecules should penetrate less into the stratum corneum to elicit ACD and PACD.

The low rates of photoaugmentation and photoinhibition of ACD are in keeping with the 2006 study, but again serve to remind clinicians of the possibility of false positive and negative reactions when conducting PPT. ${ }^{3,27}$ Irritant reactions were also rarely seen which confirms the finding of the pilot irritancy study that most organic UV absorbers can be photopatch tested at a concentration of $10 \%{ }^{8}$

There are some limitations to the study. The EMCPPTS was performed in subjects attending clinicians with suspected PACD. As a result, the frequency of PACD reported will be higher than that occurring in the European population as a whole. On a similar theme, the small numbers of subjects in certain analysed subgroups (e.g. by diagnosis) means that caution must be exercised when interpreting and extrapolating apparent patterns. The multicentre methodology of the study meant that differences in subject selection for recruitment occurred. Such differences will probably have largely accounted for the variation observed in rates of PACD between centres. Similar selection differences will also have contributed to the apparent variation in rates of PACD seen between subjects who had patches applied for $24 \mathrm{~h}$ (often from photobiology units) and those applied for $48 \mathrm{~h}$ (often from contact dermatitis units). A further limitation is that there was no accurate quantitative denominator data available in the form of the number of subjects exposed to each test agent. Therefore, for agents that led to few PACD reactions, this may reflect limited exposure rather than a low photoallergenic potential. Likewise, agents with many PACD reactions may reflect high usage, rather than a high photoallergenic potential.

In conclusion, the EMCPPTS has provided new information on the relative frequency of PACD in this selected patient group and the main photoallergens implicated. The study has also reinforced the important place of PPT, when performed according to the European consensus methodology, as an investigation in cases of possible PACD presenting to the clinician. The results obtained will be of value to interested parties in the future when deciding which agents to include in a new and up-to-date European 'baseline' photopatch test series. It also serves as a benchmark for tracking trends in PACD over time and similar studies will need to be repeated periodically to ensure agents included in photopatch test series continue to be of relevance.

\section{What's already known about this topic?}

- Organic sunscreen absorbers and topical nonsteroidal anti-inflammatory drugs (NSAIDs) are the two agent groups most commonly leading to photoallergic contact dermatitis (PACD).

- The frequency of PACD to agents in these two groups has been reported in previous multicentre studies.

- The availability to the public of agents in these two groups changes over time, as new products emerge onto the marketplace.

- Photopatch testing series require periodic updating and, currently, no European 'baseline' photopatch test series exists.

\section{What does this study add?}

- Updated information on the relative frequency of PACD to 19 organic sunscreen absorbers, including newer agents, and five topical NSAIDs currently used in Europe.

\section{Acknowledgments}

All contributors would like to thank the faculty staff members at recruiting centres for their assistance with the project. We wish to thank Bo Niklasson of Chemotechnique Diagnostics Ltd, Vellinge, Sweden for donating the test agents. We would like to thank the Health Informatics Centre (HIC) personnel at the University of Dundee, U.K. for data entry and extraction. We would also like to thank Professor Harry Moseley and Ms Lynn Fullerton of the Photobiology Unit in Dundee, U.K. for the calibration of UV meters and Drs Robert Dawe and Sally Ibbotson for their help in appraising the manuscript.

\section{References}

1 Kerr A, Ferguson J. Photoallergic contact dermatitis. Photodermatol Photoimmunol Photomed 2010; 26:56-65.

2 Bell HK, Rhodes LE. Photopatch testing in photosensitive patients. Br J Dermatol 2000; 142:589-90.

3 Bryden AM, Moseley H, Ibbotson SH et al. Photopatch testing of 1155 patients: results of the U.K. multicentre photopatch study group. Br J Dermatol 2006; 155:737-47.

4 Darvay A, White IR, Rycroft RJ et al. Photoallergic contact dermatitis is uncommon. Br J Dermatol 2001; 145:597-601.

5 Bruynzeel DP, Ferguson J, Andersen K et al. Photopatch testing: a consensus methodology for Europe. J Eur Acad Dermatol Venereol 2004; 18:679-82.

6 British Photodermatology Group. Photopatch testing-methods and indications. Br J Dermatol 1997; 136:371-6.

7 European Commission. List of permitted UV filters which cosmetic products may contain. Annex VII (Part 1). EC Health and Consumers, Cosmetic Ingredients and Substances. Available at: http://ec.europa.eu/ consumers/cosmetics/cosing/index.cfm?fuseaction=search.results \&annex_v1 = VII\&search (last accessed 2 February 2012). 
8 Kerr AC, Niklasson B, Dawe RS et al. A double-blind, randomized assessment of the irritant potential of sunscreen chemical dilutions used in photopatch testing. Contact Dermatitis 2009; 60:203-9.

9 Wahlberg JE. Patchtesting. In: Textbook of Contact Dermatitis (Rycroft R, Menne T, Frosch P, Lepoittevin JL, eds), 3rd edn. Berlin: Springer-Verlag, 2001; 939-68.

10 Bourke J, Coulson I, English J. British Association of Dermatologists' Guidelines for care of contact dermatitis. Br J Dermatol 2001; 145:877-85

11 European Commission. The implementation of good clinical practice in the conduct of clinical trials on medicinal products for human use. EC Directive 2001/20/EC. Available at: http://ec.europa. eu/health/human-use/clinical-trials/index_en.htm (last accessed 2 February 2012).

12 Hindsen $\mathrm{M}$, Isaksson $\mathrm{M}$, Persson $\mathrm{L}$ et al. Photoallergic contact dermatitis from ketoprofen induced by drug-contaminated personal objects. J Am Acad Dermatol 2004; 50:215-19.

13 Diaz RL, Gardeazabal J, Manrique $\mathrm{P}$ et al. Greater allergenicity of topical ketoprofen in contact dermatitis confirmed by use. Contact Dermatitis 2006; 54:239-43.

14 Le Coz CJ, Bottlaender A, Scrivener JN et al. Photocontact dermatitis from ketoprofen and tiaprofenic acid: cross-reactivity study in 12 consecutive patients. Contact Dermatitis 1998; 38:245-52.

15 Karlsson I, Vanden Broecke K, Martensson J et al. Clinical and experimental studies of octocrylene's allergenic potency. Contact Dermatitis $2011 ; \mathbf{6 4}: 343-52$.

16 Kerr AC. A survey of the availability of sunscreen filters in the U.K. Clin Exp Dermatol 2011; 36:541-3.

17 European Medicines Agency. Ketoprofen topical. Outcome of a procedure under article 107 of Directive 2001/83/EC. Available at: http://www.ema.europa.eu/ema/index.jsp?curl=pages/medicines/ human/referrals/Ketoprofen_topical/human_referral_000238.jsp \&murl=menus/regulations/regulations.jsp\&mid=WC0b01ac0580024e99 (last accessed 2 February 2012).

18 Avenel-Audran M, Dutartre H, Goossens A et al. Octocrylene, an emerging photoallergen. Arch Dermatol 2010; 146:753-7.

19 Wilkinson DS. Photodermatitis due to tetrachlorsalicylanilide. Br J Dermatol 1961; 73:213-19.

20 Kerr AC, Muller F, Ferguson J et al. Occupational carprofen photoallergic contact dermatitis. Br J Dermatol 2008; 159:1303-8.

21 Goday Bujan JJ, Perez Varela L, Pineyro Molina F et al. Allergic and photoallergic contact dermatitis from etofenamate: study of 14 cases. Contact Dermatitis 2009; 61:118-20.

22 Andrade P, Goncalo M, Figueiredo A. Allergic contact dermatitis to decyl glucoside in Tinosorb M. Contact Dermatitis 2010; 62:11920.

23 Leyden JJ, Kligman AM. Allergic contact dermatitis: sex differences. Contact Dermatitis 1977; 3:333-6.

24 Rees JL, Friedmann PS, Matthews JN. Sex differences in susceptibility to development of contact hypersensitivity to dinitrochlorobenzene (DNCB). Br J Dermatol 1989; 120:371-4.

25 Frain-Bell W, Johnson BE. Contact allergic sensitivity to plants and the photosensitivity dermatitis and actinic reticuloid syndrome. Br J Dermatol 1979; 101:503-12.

26 Menage H, Ross JS, Norris PG et al. Contact and photocontact sensitization in chronic actinic dermatitis: sesquiterpene lactone mix is an important allergen. Br J Dermatol 1995; 132:543-7.

27 Beattie PE, Traynor NJ, Woods JA et al. Can a positive photopatch test be elicited by subclinical irritancy or allergy plus suberythemal UV exposure? Contact Dermatitis 2004; 51:235-40.

\section{Appendix}

A.C. Kerr, J. Ferguson (Ninewells Hospital, Dundee, U.K.); A.K. Haylett, L.E. Rhodes (University of Manchester, Salford Royal NHS Foundation Trust, Manchester, U.K.); H. Adamski (University of Rennes, Rennes, France); A. Alomar, E. Serra (Hospital St Creu i St Pau, Barcelona, Spain); C. Antoniou (Andeas Sygros Hospital, Athens, Greece); F. Aubin, M. Vigan (University Hospital, Besançon, France); T. Biedermann, J. Fischer (University of Tübingen, Germany); J.-L. Bourrain (University of Grenoble, Grenoble, France); D. Bruynzeel, T. Rustemeyer (VU University Medical Centre, Amsterdam, the Netherlands); J.M. Carrascosa (Hospital Universitari Germans Trias i Pujol, Badalona, Spain); M.M.U. Chowdhury (University Hospital of Wales, Cardiff, U.K.); J. de la Cuadra (Hospital General, Valencia, Spain); C. Foti (University of Bari, Bari, Italy); J. Gardeazabal (Hospital Cruces, Bilbao, Spain); D.J. Gawkrodger (Royal Hallamshire Hospital, Sheffield, U.K.); A. Gimenez-Arnau (Hospital del Mar, Universitat Autònoma, Barcelona, Spain); M. Goncalo (Coimbra University, Coimbra, Portugal); A. Goossens (University Hospital, Leuven, Belgium); S.H. Ibbotson, R.S. Dawe (Ninewells Hospital, Dundee, U.K.); M. Lecha (University of Barcelona, Barcelona, Spain); M.-C. Marguery (Larrey University Hospital, Toulouse, France); N.J. Neumann (Heinrich-Heine University, Dusseldorf, Germany); B. Niklasson (Chemotechnique Diagnostics, Vellinge, Sweden); J.-L. Peyron (Hopital Saint Eloi, Montpellier, France); P. Pigatto (IRCCS Galeazzi Hospital, University of Milan, Milan, Italy); R. Spiewak (Jagiellonian University, Krakow, Poland); N. Stone (Royal Gwent Hospital, Newport, U.K.); A. Tanew (Medical University of Vienna, Vienna, Austria); P. Thomas, A. Bonnevalle (Hopital Claude Huriez, Lille, France); S.M. Wilkinson (Leeds General Infirmary, Leeds, U.K.); P. Wolf, A. Gruber-Wackernagel (Medical University of Graz, Graz, Austria); H.C. Wulf (Bispebjerg Hospital, University of Copenhagen, Copenhagen, Denmark).

\section{Supporting information}

Additional supporting information is available in the online version of this article.

Appendix S1 Study proforma.

Appendix S2 Frequency of PACD at each recruiting centre.

Appendix S3 PACD reactions with COADEX assignations.

Appendix S4 Rates of PACD to the agents ketoprofen, etofenamate, octocrylene and benzophenone-3 in each country.

Appendix S5 COADEX assignations in the 15 subjects who had concomitant PACD reactions to benzophenone-3, octocrylene and ketoprofen.

Please note: Wiley-Blackwell are not responsible for the content or functionality of any supporting materials supplied by the authors. Any queries (other than missing material) should be directed to the corresponding author for the article. 